Article

\title{
A Blind Calibration Model for I/Q Imbalances of Wideband Zero-IF Receivers
}

\author{
Xiaoye Peng, Zhiyu Wang, Jiongjiong Mo, Chenge Wang *, Jiarui Liu $@$ and Faxin Yu
}

Institute of Astronautic Electronic Engineering, School of Aeronautics and Astronautics, Zhejiang University, Hangzhou 310007, China; dawn_xypeng@zju.edu.cn (X.P.); zywang@zju.edu.cn (Z.W.);

jiongjiongmo@zju.edu.cn (J.M.); jrliu@zju.edu.cn (J.L.); fxyu@zju.edu.cn (F.Y.)

* Correspondence: wcghha@zju.edu.cn; Tel.: +86-0571-87951581

Received: 6 August 2020; Accepted: 4 November 2020; Published: 6 November 2020

check for updates

\begin{abstract}
Frequency-dependent I/Q imbalance and frequency-independent I/Q imbalance are the major impairments in wideband zero-IF receivers, and they both cannot be ignored. In this paper, a blind calibration model is designed for compensating these I/Q imbalances. In order to accurately estimate the imbalance parameters with low cost, a classification rule is proposed according to the frequency-domain statistical characteristics of the received signal. The calibration points in the frequency-domain are divided into two groups. Then, the amplitude imbalance and the frequency-dependent phase imbalance are derived from the group of signal points and, separately, the frequency-independent phase imbalance is calculated from the group of noise points. In the derivation of the frequency-dependent phase imbalance, a general fitting model suitable for all signal points is proposed, which does not require special calculations for either DC point or $\mathrm{f}_{\mathrm{s}} / 2$ point. Then, a finite impulse response (FIR) real-valued filter is designed to correct the impairments of received signal. The performances of the proposed calibration model are evaluated through both simulations and experiments. The simulation results show the image rejection ratio (IRR) improvement to around 35-45 dBc at high signal-to-noise ratio (SNR). Based on the mismatched data of the ADRV9009 evaluation board, the experimental results exhibit the IRR improvement of both multi-tone and wideband signals to about $30 \mathrm{dBc}$.
\end{abstract}

Keywords: wideband zero-IF receivers; I/Q imbalances; frequency-domain statistical characteristics; FIR real-valued filter

\section{Introduction}

Nowadays wireless communication is everywhere, Figure 1 shows a common wireless communication system application scenario. With the innovation of communication systems and the introduction and wide application of new technologies and protocols, the problem of mismatch between hardware and software systems and communication protocol compatibility among different communication terminals has become increasingly serious [1]. In order to solve this problem, software-defined radio (SDR) is proposed, which receives various wireless signals in the air and performs digital processing on them to achieve a system that can realize various wireless communication functions [2]. 


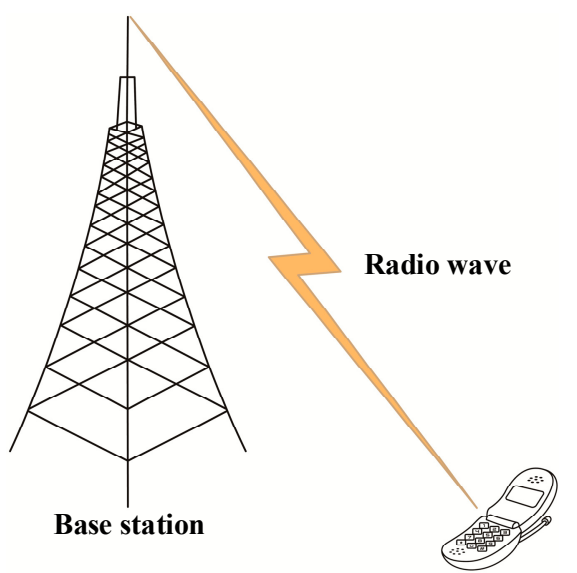

Mobile communication equipment

Figure 1. The common wireless communication system application scenario.

Compared with superheterodyne receivers, zero-IF receivers have become the main SDR radio frequency (RF) front-end receivers due to their simple structure, high integration, small size, low cost and low power consumption [3]. As shown in the Figure 2, the SDR system can be divided into SDR front-end and SDR back-end. The front-end is mainly composed of a RF analog channel, a digital-to-analog converter (ADC) module and a digital channel, and the back-end is mainly composed of a baseband module to process baseband signals. Between the analog channel and the baseband module of the zero-IF receiver, the digital channel generally includes a filter, IQ calibration and other sub-modules. The digital channel and baseband module are connected through an interface protocol to transmit signals in different clock domains. The digital channel is the core part of the software radio system. It is necessary to design a reasonable digital channel to ensure compatibility, efficiency and scalability of the SDR system.

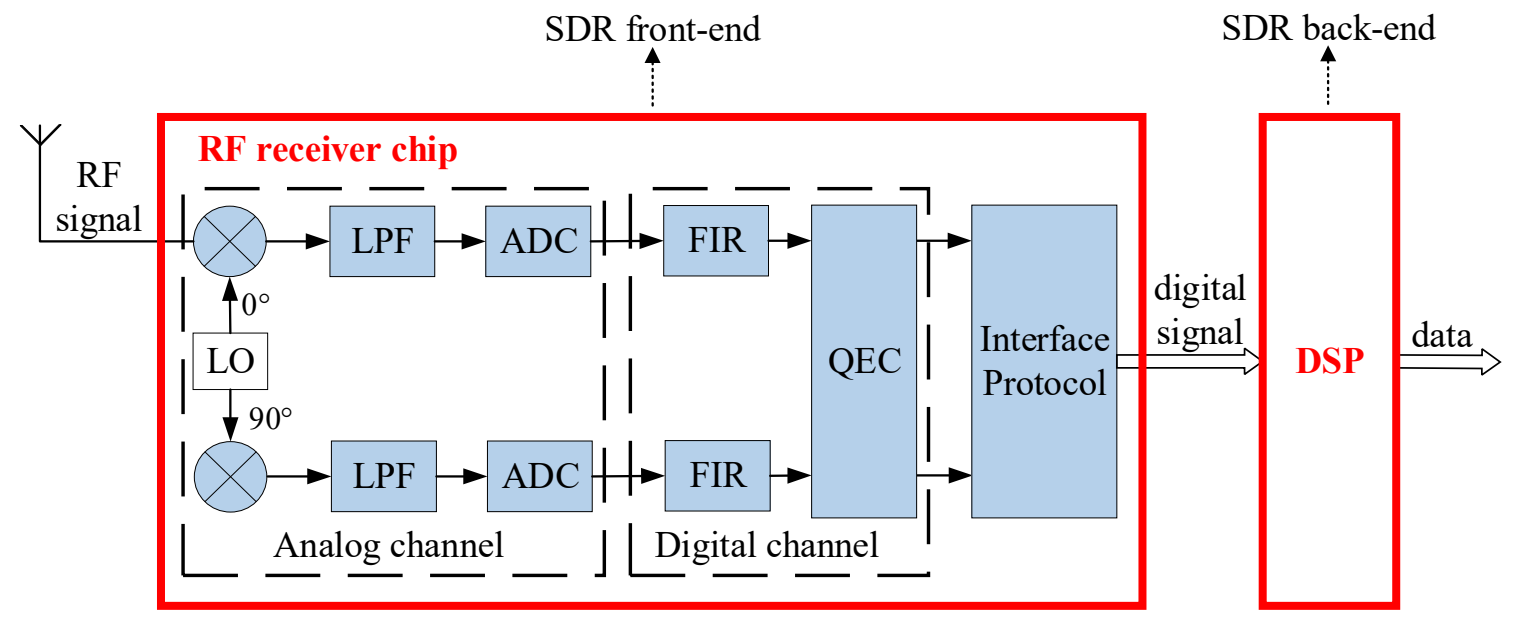

Figure 2. Software-defined radio (SDR) system architecture diagram.

In a zero-IF receiver, the received signal is directly quadrature down-converted from RF to a baseband signal without the need for an external image frequency suppression filter. The principle of zero-IF topology is an orthogonal structure, its goal is to obtain two baseband signals of the same frequency with the same amplitude and a phase difference of $90^{\circ}$. However, due to factors such as analog device mismatch [4], I/Q imbalance is caused, which produces useless image interference signals and affects the demodulation performance of the baseband signal [5].

The I/Q mismatch in the wideband zero-IF receiver is caused by two different sources: (1) the amplitude imbalance and phase error of the local oscillator (LO) signals of the quadrature mixer 
are commonly considered to be frequency-independent for a certain LO frequency [6-8]. (2) The frequency-dependent imbalances may include contributions from the ADCs and the low-pass filters (LPFs), as well as the signal paths themselves [9]. For a wideband received signal, the dispersion of the frequency response of the analog devices within a zero-IF receiver usually cannot be ignored. Therefore, both types of imbalance in the calibration scheme of the wideband zero-IF receiver have to be considered.

The current digital domain I/Q imbalance calibration algorithm is mainly divided into training sequence methods and blind methods according to whether data assistance is needed during calibration. Reference [10-16] make relevant research on I/Q calibration based on training sequence method. The authors in [10-15] send a designed training sequence before the useful signal, then analyze the training sequence and the received mismatch sequence to estimate the imbalance parameters. The author of [16] proposed a novel algorithm called two-dimensional decomposition look-up table (TDD-LUT), which can decompose mixed mismatches and reconstruct the compensation process according to different receiver configurations to correct the I/Q imbalances, this algorithm needs to send a training sequence. However, the methods described above need to design a specific training sequence for different communication protocols and require a short break in normal operation.

Blind calibration does not require data assistance or other additional information, such as the modulation method of the signal. It only uses the inherent characteristics of the received signal to estimate the channel imbalance parameters. At present, blind calibration is mainly divided into the calibration based on blind source separation (BSS) techniques [17-20] and the calibration based on signal statistical characteristics [21-28]. The authors in [17] used the Cholesky decomposition of the covariance matrix of the received signal and the adaptive algorithm to extract the imbalances. In [18], the authors designed two BSS algorithms and used a constrained non-linear function in the conventional equivariant adaptive separation via independence (EASI) algorithm to compensate for the phase shift of the I/Q channels. The authors proposed advanced BSS techniques for frequency-independent I/Q imbalance compensation in MIMO systems in [19]. The authors of [20] proposed a new adaptive algorithm to compensate the IQ imbalance problem of quadratic receivers, which is based on the combination between the backward blind source separation (BBSS) structure and the fast Newton transversal filter (FNTF) technique, and the complexity of the algorithm is related to its selected prediction order.

The blind algorithm based on the statistical characteristics of the signal has lower computational complexity than the BSS techniques. In [21,22], the authors proposed a blind calibration algorithm based on the non-correlation of IQ components. This algorithm only uses real-value multipliers to complete the mismatch compensation, but this method is not good for signal calibration with larger bandwidth. The authors provided I/Q compensation algorithms in the time-domain, which recover the circularity or properness of the received signal in [23-25]. The authors of [26] constructed the I/Q imbalance compensation problem as a linear minimum mean square error (MMSE) estimation problem based on the equi-absolute variance condition and the properness condition of the signal, and proposes two blind adaptive I/Q imbalance compensation algorithms based on LMS and RLS adaptation algorithms. The author in [27] proposed a blind estimation algorithm for I/Q imbalance parameters based on joint first and second order statistics (FSS) which has a lower complexity than conventional Gaussian maximum likelihood estimation (GMLE). In [28], the authors designed an adaptive blind two-stage compensator by using real-valued filter, and determined the initial value, step-size and convergence range of the iteration by analyzing the conditions of compensator parameter stability. The authors of [29] proposed two frequency-dependent blind calibration algorithms. The first is to calculate the compensation filter matrix in an iterative manner in the time domain. The second is a frequency-domain approach for orthogonal frequency-division multiplexing (OFDM) systems, the compensation filter in which is designed in a closed-form. The authors in [30,31] also estimated the I/Q imbalance parameters in the frequency domain. Compared with time-domain methods, the methods in [30,31] do not require waiting for iterative parameter convergence. However, these frequency-domain algorithms use some 
useless information when estimating imbalance parameters, which introduces additional errors. And the length of the designed digital compensation filters are long, making the flatness of the frequency response poor, reducing IRR, and increasing the resource cost.

This paper proposes a blind calibration model for I/Q imbalance based on the statistical characteristics of the received signal in the frequency-domain. The first step is to condition the data, then we perform DC calibration, grouping, windowing and fast Fourier transform (FFT). Then, we propose a frequency point classification rule by analyzing the distribution characteristics of frequency-independent imbalance and frequency-dependent imbalance, and classify the frequency points on the baseband into two types (noise points and signal points). The calibration points used were selected according to the imbalance parameters. We also propose a general fitting method applicable to any frequency point, thereby simplifying the calculation process of phase-dependent imbalance parameters. Finally, a FIR real-valued filter with short filter length is designed to compensate I/Q imbalances. In order to verify the algorithm in this paper, simulations and experiments are carried out.

The remainder of this paper is organized as follows. Section 2 presents the zero-IF receiver I/Q imbalance structure. Section 3 provides the I/Q imbalance calibration model. Section 4 shows simulation results for different scenarios and Section 5 uses actual data to verify the proposed model. Finally, Section 6 concludes the paper.

\section{I/Q Imbalance Analysis}

In an ideal zero-IF receiver, the two LO signals of the mixer have the same frequency, equal amplitude and an exact $90^{\circ}$ relative phase difference, which can be expressed as $\cos 2 \pi \mathrm{f}_{\mathrm{c}} \mathrm{t}$ and $-\sin 2 \pi \mathrm{f}_{\mathrm{c}} \mathrm{t}$. The I/Q channels mainly include LPFs and ADCs, and their effects on the signal can be combined and expressed as $\mathrm{H}_{\mathrm{I}}(\mathrm{f})$ and $\mathrm{H}_{\mathrm{Q}}(\mathrm{f})$, and the frequency response has the following relationship $\left|\mathrm{H}_{\mathrm{I}}(\mathrm{f})\right|=\left|\mathrm{H}_{\mathrm{Q}}(\mathrm{f})\right|$ and $\angle \mathrm{H}_{\mathrm{I}}(\mathrm{f})=\angle \mathrm{H}_{\mathrm{Q}}(\mathrm{f})$.

The block diagram of the actual receiver model is shown in Figure 3. The amplitudes of the two LO signals are unequal and the phases are not orthogonal, resulting in frequency-independent amplitude imbalance $\alpha$ and phase imbalance $\varphi$. The mismatch of LPFs and ADCs in the two baseband channels results in frequency-dependent amplitude imbalance $M(f)$ and phase imbalance $\theta(f)$. The frequency response difference between the I- and Q-branch is:

$$
\frac{\mathrm{H}_{\mathrm{Q}}(\mathrm{f})}{\mathrm{H}_{\mathrm{I}}(\mathrm{f})}=\mathrm{M}(\mathrm{f}) \mathrm{e}^{\mathrm{j} \theta(\mathrm{f})}
$$

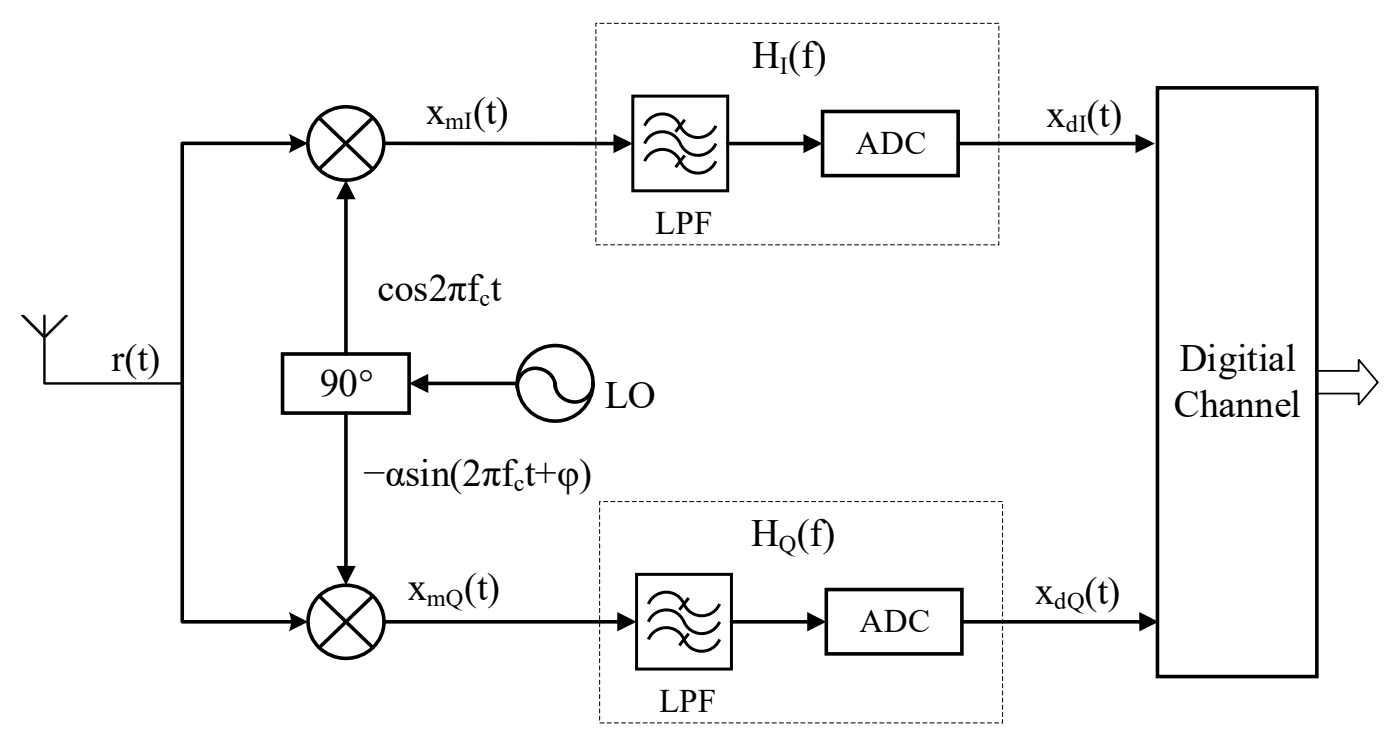

Figure 3. Typical structure of a zero-IF receiver. 
The frequency-independent amplitude imbalance $\alpha$ is a constant and the frequency-dependent amplitude imbalance $M(f)$ is an even function, which has $M(-f)=M(f)$, so we merge $\alpha$ into $M(f)$ for simplification. The phase imbalance $\varphi$ is a constant and the phase imbalance $\theta(f)$ is an odd function, which has $\theta(-f)=-\theta(f)$, so these two parameters cannot be combined.

This paper mainly studies the I/Q imbalance calibration of the receiver. Since the carrier frequency offset and phase offset have no effect on the relative deviation of the IQ component [32], these two parameters are ignored in this paper. We assume $\mathrm{z}(\mathrm{t})=\mathrm{z}_{\mathrm{I}}(\mathrm{t})+\mathrm{jz} \mathrm{z}_{\mathrm{Q}}(\mathrm{t})$ is an ideal baseband signal and $\mathrm{f}_{\mathrm{c}}$ is the carrier frequency, then the expression of the received RF signal $r(t)$ is:

$$
\begin{aligned}
r(t) & =2 \operatorname{Re}\left[z(t) e^{j 2 \pi f_{c} t}\right] \\
= & z(t) e^{j 2 \pi f_{c} t}+z(t)^{*} e^{-j 2 \pi f_{c} t},
\end{aligned}
$$

The received RF signal is mixed with the LO signal first, and then the baseband signal is obtained through the LPFs and ADCs. The mathematical model of this process is:

$$
\begin{aligned}
\mathrm{x}_{\mathrm{d}}(\mathrm{t}) & =\mathrm{x}_{\mathrm{mI}}(\mathrm{t}) \otimes \mathrm{h}_{\mathrm{I}}(\mathrm{t})+j \mathrm{x}_{\mathrm{mQ}}(\mathrm{t}) \otimes \mathrm{h}_{\mathrm{Q}}(\mathrm{t}) \\
& =\left\{\mathrm{r}(\mathrm{t}) \bullet \cos 2 \pi \mathrm{f}_{\mathrm{c}} \mathrm{t}\right\} \otimes \mathrm{h}_{\mathrm{I}}(\mathrm{t})+\mathrm{j}\left\{\mathrm{r}(\mathrm{t}) \bullet\left[-\sin \left(2 \pi \mathrm{f}_{\mathrm{c}} \mathrm{t}+\varphi\right)\right]\right\} \otimes \mathrm{h}_{\mathrm{Q}}(\mathrm{t}) \\
& =\mathrm{z}(\mathrm{t}) \otimes \frac{1}{2}\left[\mathrm{~h}_{\mathrm{I}}(\mathrm{t})+\mathrm{e}^{-\mathrm{j} \varphi} \mathrm{h}_{\mathrm{Q}}(\mathrm{t})\right]+\mathrm{z}(\mathrm{t})^{*} \otimes \frac{1}{2}\left[\mathrm{~h}_{\mathrm{I}}(\mathrm{t})-\mathrm{e}^{\mathrm{j} \varphi} \mathrm{h}_{\mathrm{Q}}(\mathrm{t})\right]
\end{aligned}
$$

where $h_{I}(t)$ and $h_{Q}(t)$ are the time-varying channel response of $I / Q$ channels respectively, $\otimes$ denotes the convolution. The frequency-domain expression of Equation (3) is:

$$
X_{d}(f)=Z(f) G_{1}(f)+Z^{*}(-f) G_{2}(f)
$$

with,

$$
\left\{\begin{array}{l}
\mathrm{G}_{1}(\mathrm{f})=\frac{1}{2}\left[\mathrm{H}_{\mathrm{I}}(\mathrm{f})+\mathrm{e}^{-\mathrm{j} \varphi} \mathrm{H}_{\mathrm{Q}}(\mathrm{f})\right] \\
\mathrm{G}_{2}(\mathrm{f})=\frac{1}{2}\left[\mathrm{H}_{\mathrm{I}}(\mathrm{f})-\mathrm{e}^{\mathrm{j} \varphi} \mathrm{H}_{\mathrm{Q}}(\mathrm{f})\right]
\end{array}\right.
$$

In Equation (4), $Z(f) G_{1}(f)$ represents the main signal component, and $Z^{*}(-f) G_{2}(f)$ represents the image signal component caused by the I/Q imbalances, so the IRR of the mismatched baseband signal can be written as:

$$
\operatorname{IRR}(f)=10 \log _{10} \frac{\left|\mathrm{Z}(\mathrm{f}) \mathrm{G}_{1}(\mathrm{f})\right|^{2}}{\left|\mathrm{Z}^{*}(\mathrm{f}) \mathrm{G}_{2}(\mathrm{f})\right|^{2}}=10 \log _{10} \frac{\left|\mathrm{G}_{1}(\mathrm{f})\right|^{2}}{\left|\mathrm{G}_{2}(\mathrm{f})\right|^{2}},
$$

A simulation is carried out based on the theoretical analysis, with the results shown in Figure 4. The imbalance will be affected drastically with the increasing of the phase deviation or the amplitude imbalance. From the results shown in Figure $4 a$, when $|\theta|$ is less than $1^{\circ}$ and $|M-1|$ is less than 0.0198 , the IRR is greater than $40 \mathrm{dBc}$. As shown in the detailed zoom-in view of Figure $4 \mathrm{~b}$, when $|\theta|$ is less than $0.002^{\circ}$ and $|\mathrm{M}-1|$ is less than $3.5 \times 10^{-5}$, the IRR reaches $95 \mathrm{dBc}$. Therefore, a high IRR requires high accuracy in estimating imbalance parameters. 


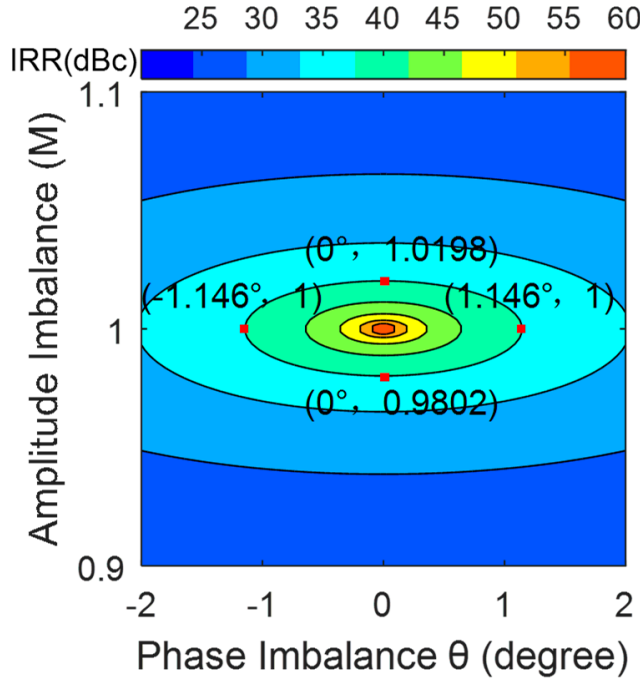

(a)

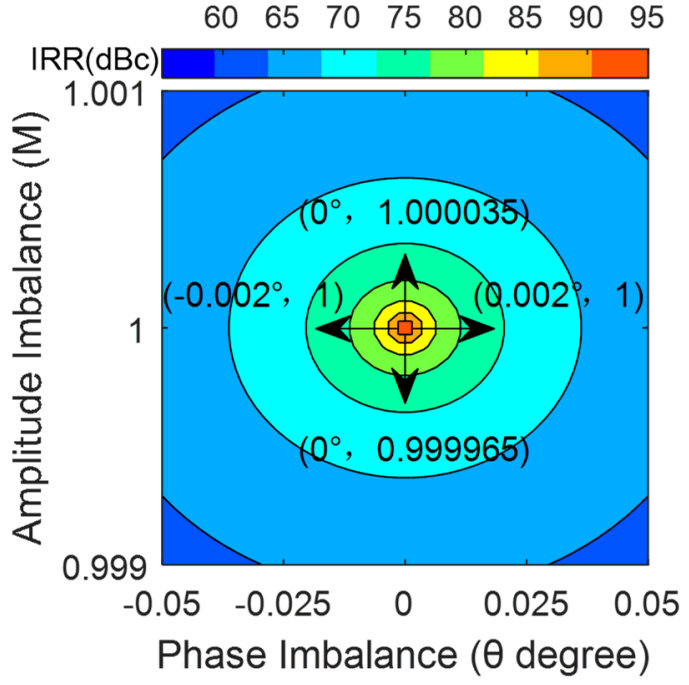

(b)

Figure 4. The simulated IRR as functions of the amplitude imbalance $M$ and the phase imbalance $\theta$, suppose $\varphi=0$. (a) The IRR versus $M$ and $\theta$; (b) The zoom-in view for the case when IRR $>60 \mathrm{dBc}$.

\section{I/Q Imbalance Calibration Model}

This paper proposes an I/Q imbalance blind calibration model, as shown in Figure 5. The imbalance baseband signal output from the ADCs needs to be analyzed and processed by several modules in Figure 5, the imbalance parameters $\varphi, M(f), \theta(f)$ are calculated, and then the I/Q imbalances are compensated. This calibration model is explained in detail below.

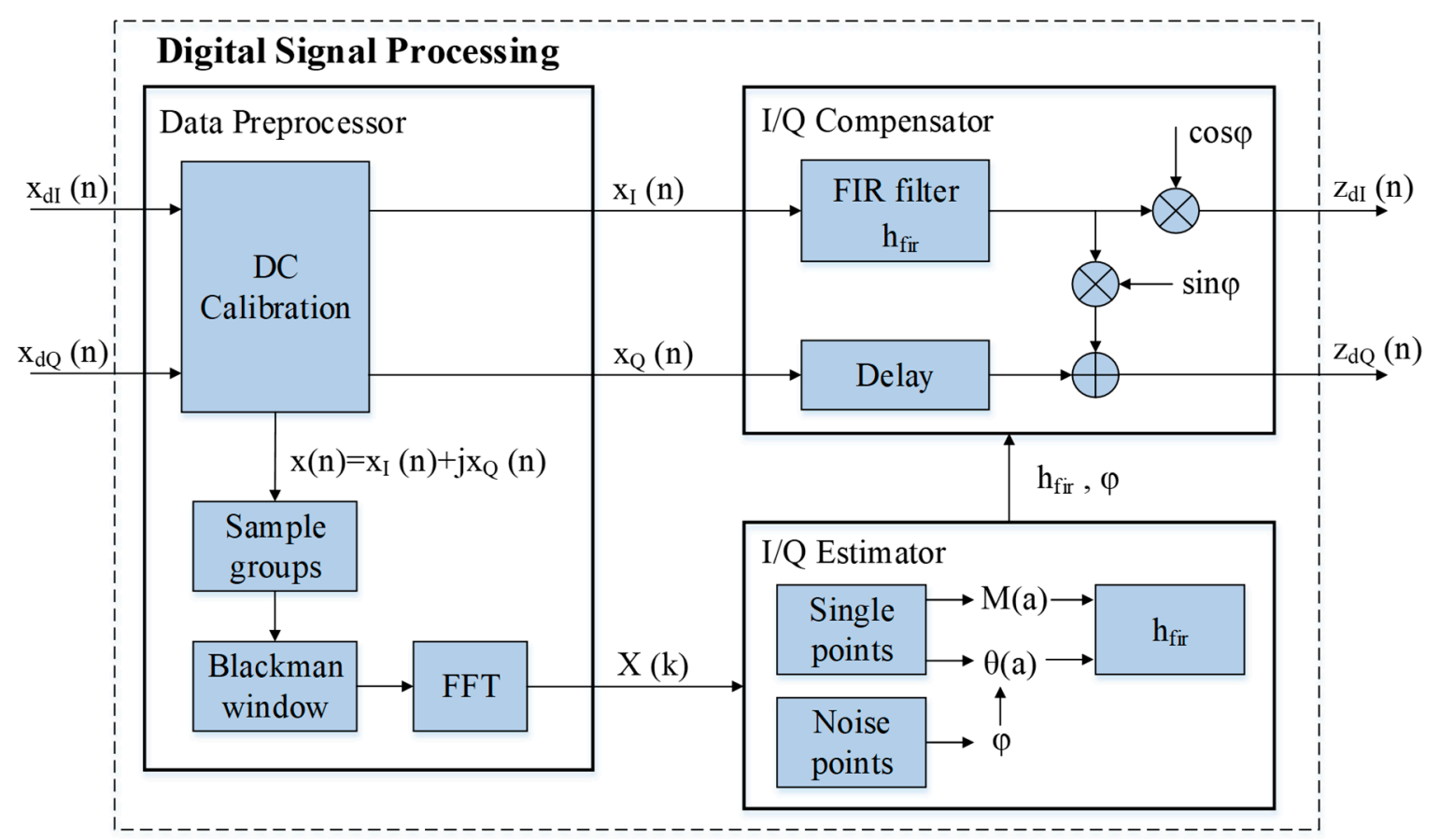

Figure 5. I/Q imbalance calibration model.

\subsection{Data Preprocessing}

Data preprocessing is mainly to perform DC calibration, grouping, windowing and FFT on the received baseband signal to reduce the influence of DC offset and energy leakage on the estimation 
accuracy of subsequent algorithms. During the operation of the zero-IF receiver, the mismatch between the in-phase signal path and quadrature phase signal path and the LO self-mixing cause a DC offset in the received signal [33]. This phenomenon will destroy the statistics of the baseband signal, especially the information near DC, so DC offset calibration must be performed first. The DC calibration algorithm is shown in Equation (6), the data $\mathrm{x}(\mathrm{n})$ after DC calibration is obtained by subtracting the average value of the input data $x_{d}(n)$.

$$
x(n)=x_{d}(n)-\frac{1}{K} \sum_{n=0}^{K-1} x_{d}(n),
$$

The data after DC calibration is grouped, assuming that there are $\mathrm{K}=\mathrm{N} \times \mathrm{W}$ data, which are divided into $\mathrm{W}$ groups, each group with $\mathrm{N}$ data. The amount of data in each group determines the length of the FFT and also determines the location of the frequency points. In this paper, we call these frequency points calibration points. Assuming $\mathrm{f}_{\mathrm{s}}$ is the sampling rate of baseband signal in the digital domain, $\mathrm{N}$ is the number of calibration points, the calibration points are evenly distributed over the whole frequency band, and the frequency of each calibration point is:

$$
\mathrm{f}_{\mathrm{b}}=\frac{\mathrm{mf}_{\mathrm{s}}}{\mathrm{N}}, \mathrm{m}=0, \ldots, \mathrm{N}-1,
$$

The model proposed in this paper is to calculate the imbalance parameters at the calibration points, so the amplitude spectrum accuracy at the calibration frequency is required to be high. However, the signal spectrum leakage will greatly affect the accuracy of the calculation, and it is necessary to select a window function with small side lobe peak value, large attenuation amplitude and fast attenuation [34] to reduce the spectrum leakage. Unlike the windowing methods proposed in previous works, we select the blackman window. Finally, the data are subjected to FFT to obtain the corresponding frequency domain data matrix.

\subsection{I/Q Imbalance Estimation}

This module proposes a novel I/Q imbalance parameter estimation method, which improves the estimation accuracy of imbalance parameters with low cost. In the related research of I/Q mismatch compensation using the frequency-domain statistical characteristics of the signal, some literatures assume that $Z(\mathrm{f})$ is uncorrelated in the frequency domain, and the ideal baseband signal satisfies $\mathrm{E}\{\mathrm{Z}(\mathrm{f}) \mathrm{Z}(-\mathrm{f})\}=0$ and $\mathrm{E}\left\{\mathrm{Z}(\mathrm{f}) \mathrm{Z}^{*}(-\mathrm{f})\right\}=0$. Therefore, the relationship between the received signal and the imbalance parameter [29-31], namely the following two Equations (8) and (9), where E\{\} denotes expectation. It is worth noting that, when calculating different types of imbalance parameter, the choice of frequency point is the key. In order to achieve accurate imbalance parameters, we propose a calibration point classification rule, which divides the calibration points into signal points and noise points, and then calculates the imbalance parameters in a targeted manner.

$$
\begin{aligned}
& M(k)=\sqrt{\frac{E\left\{\left|X(k)-X^{*}(N-k)\right|_{2}\right\}}{E\left\{\left|X(k)+X^{*}(N-k)\right|_{2}\right\}}}, \\
& \operatorname{Im}(\mathrm{E}\{\mathrm{X}(\mathrm{k}) \mathrm{X}(\mathrm{N}-\mathrm{k})\}) \\
& =\frac{1}{2} \mathrm{E}\left\{|\mathrm{X}(\mathrm{k})|_{2}-|\mathrm{X}(\mathrm{N}-\mathrm{k})|_{2}\right\} \bullet \theta(\mathrm{k})-\frac{1}{2} \mathrm{M}(\mathrm{k}) \mathrm{E}\left\{\left|\mathrm{X}(\mathrm{k})+\mathrm{X}^{*}(\mathrm{~N}-\mathrm{k})\right|_{2}\right\} \bullet \varphi{ }^{\prime}
\end{aligned}
$$

The entire baseband of a zero-IF receiver contains frequency-independent imbalances, and the noise within the operating frequency range of the communication system is generally white Gaussian noise, which satisfies $E\left\{|X(k)|^{2}\right\}-E\left\{|X(N-k)|^{2}\right\} \approx 0$ in Equation (9). In addition, it is meaningless to estimate $\mathrm{M}(\mathrm{k})$ and $\theta(\mathrm{k})$ at all calibration points $(0$ to $\mathrm{N}-1)$ by using Equation (8) and Equation (9), because the noise contains almost no information about frequency-dependent imbalances. Therefore, as shown in 
Figure 6, we divide $\mathrm{N}$ calibration points into signal points and noise points. The imbalance parameter $\varphi$ is calculated by the noise points, $\mathrm{M}(\mathrm{k})$ and $\theta(\mathrm{k})$ are calculated by the signal points. Due to spectrum leakage, the amplitude value of the calibration points near the signal is relatively large. Based on the above analysis, the following provisions are made for the classification of calibration points:

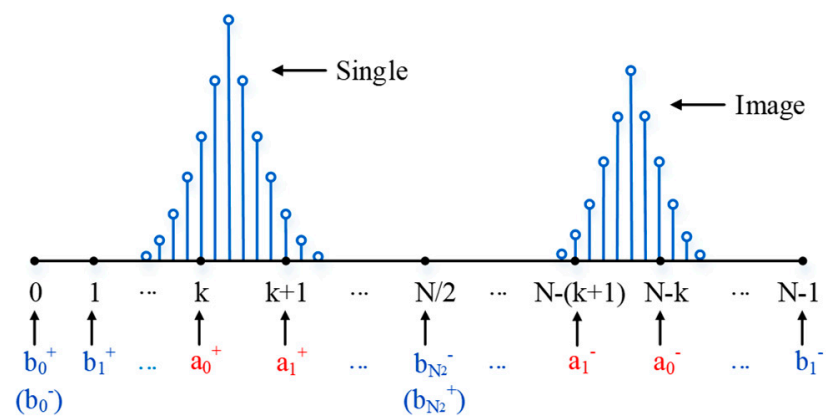

Figure 6. Correction signal classification diagram.

- Among the calibration points on $0-\mathrm{f}_{\mathrm{s}} / 2(0-\mathrm{N} / 2)$, the top $\mathrm{N}_{1}$ points with the largest amplitude value $|\mathrm{X}(\mathrm{k})|$ of the calibration points are chosen as the signal points $a_{0}^{+} \sim \mathrm{a}_{N_{1}-1}^{+}$.

- The symmetrical calibration points $\mathrm{a}^{-}=\mathrm{N}-\mathrm{a}^{+}$on $\mathrm{f}_{\mathrm{s}} / 2-\mathrm{f}_{\mathrm{s}}(\mathrm{N} / 2-\mathrm{N})$ are also signal points.

- Except for the signal points, the other calibration points are noise points.

- The symmetry points of the 0 point and the $\mathrm{N} / 2$ point are themselves.

The method of classifying calibration points proposed in this paper to calculate imbalance parameters separately has the following advantages.

- Separating the frequency-independent imbalance parameter $\varphi$ and the frequency-dependent imbalance parameter $\theta(\mathrm{k})$ in Equation (9).

- When calculating $\mathrm{M}(\mathrm{k})$ and $\theta(\mathrm{k})$, reduce the error caused by useless noise points.

- Separating the calibration points can reduce the filter length (reduce from $N$ to $2 N_{1}$ ) and resource consumption.

The set of calibration points, signal points and noise points can be expressed as:

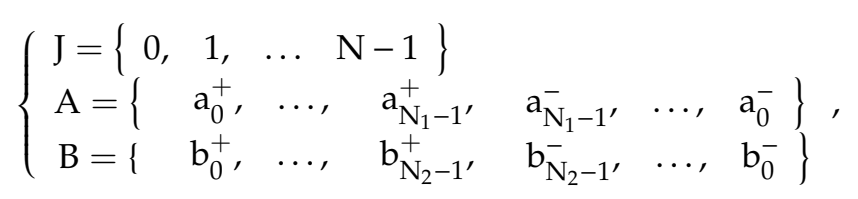

where $\mathrm{J}=\mathrm{A} \cup \mathrm{B}, \mathrm{A}$ and $\mathrm{B}$ complement each other. Because the symmetry points at 0 and N/2 are themselves, we have $N=2 N_{1}+2 N_{2}-2$. Since $M(k)$ is an even function and $\theta(k)$ is an odd function, both the imbalance parameters at positive frequencies $\left(\mathrm{a}_{0}^{+} \leq \mathrm{k} \leq \mathrm{a}_{\mathrm{N}_{1}-1}^{+}\right)$are calculated from $\mathrm{A}$, and then the imbalance parameters at the negative frequencies can be obtained according to the symmetry.

Through the above analysis, the expression for calculating the amplitude imbalance parameter $\mathrm{M}$ at the signal is:

$$
\mathrm{M}(\mathrm{a})=\sqrt{\frac{\mathrm{E}\left\{\left|X(\mathrm{a})-\mathrm{X}^{*}(\mathrm{~N}-\mathrm{a})\right|_{2}\right\}}{\mathrm{E}\left\{\left|X(\mathrm{a})+\mathrm{X}^{*}(\mathrm{~N}-\mathrm{a})\right|_{2}\right\}}} \quad, \mathrm{a}=\mathrm{a}_{0}^{+}, \mathrm{a}_{1}^{+}, \ldots, \mathrm{a}_{\mathrm{N}_{1}-1}^{+},
$$

At the noise points, $\theta(b)=0$, then Equation (9) can be written as:

$$
\operatorname{Im}(E\{X(b) X(N-b)\})=-\frac{1}{2} M(b) E\left\{\left|X(b)+X^{*}(N-b)\right|^{2}\right\} \bullet \varphi,
$$

where $b=b_{0}^{+}, b_{1}^{+}, \ldots, b_{\mathrm{N}_{2}-1}^{+}$. 
For simplification, we set:

$$
\left\{\begin{array}{l}
S(b)=-\frac{1}{2} M(b) E\left\{\left|X(b)+X^{*}(N-b)\right|_{2}\right\} \\
R(b)=\operatorname{Im}(E\{X(b) X(N-b)\})
\end{array}, b=b_{0}^{+}, b_{1}^{+}, \ldots, b_{N_{2}-1}^{+}\right.
$$

Then, a fitting model of $\varphi$ can be established as:

$$
\mathrm{S} \bullet \varphi=\mathrm{R},
$$

In Equation (14), $\mathrm{S}=\left[\mathrm{S}\left(\mathrm{b}_{0}^{+}\right), \mathrm{S}\left(\mathrm{b}_{1}^{+}\right), \ldots \mathrm{S}\left(\mathrm{b}_{\mathrm{N}_{2}-1}^{+}\right)\right]^{\mathrm{T}}$ and $\mathrm{R}=\left[\mathrm{R}\left(\mathrm{b}_{0}^{+}\right), \mathrm{R}\left(\mathrm{b}_{1}^{+}\right), \ldots \mathrm{R}\left(\mathrm{b}_{\mathrm{N}_{2}-1}^{+}\right)\right]^{\mathrm{T}}$. According to the least squares [35], the linear fitting objective function is:

$$
\min (\mathrm{R}-\mathrm{S} \varphi)^{\mathrm{T}} \bullet(\mathrm{R}-\mathrm{S} \varphi),
$$

The equation for calculating the constant $\varphi$ is:

$$
\varphi=\left(S^{\mathrm{T}} \mathrm{S}\right)^{-1} \mathrm{~S}^{\mathrm{T}} \bullet \mathrm{R},
$$

Then the signal points are used to calculate $\theta$. We bring $\varphi$ into Equation (9) to obtain (17).

$$
\begin{aligned}
& \frac{1}{2} \mathrm{E}\left\{|\mathrm{X}(\mathrm{a})|_{2}-|X(\mathrm{~N}-\mathrm{a})|_{2}\right\} \bullet \theta(\mathrm{a}) \\
& =\operatorname{Im}(\mathrm{E}\{\mathrm{X}(\mathrm{a}) \mathrm{X}(\mathrm{N}-\mathrm{a})\})+\frac{1}{2} \mathrm{M}(\mathrm{a}) \mathrm{E}\left\{\left|\mathrm{X}(\mathrm{a})+\mathrm{X}^{*}(\mathrm{~N}-\mathrm{a})\right|_{2}\right\} \bullet \varphi
\end{aligned}
$$

where $\mathrm{a}=\mathrm{a}_{0}^{+}, \mathrm{a}_{1}^{+}, \ldots, \mathrm{a}_{\mathrm{N}_{1}-1}^{+}$.

We make:

$$
\left\{\begin{array}{l}
\mathrm{P}(\mathrm{a})=\frac{1}{2} \mathrm{E}\left\{|\mathrm{X}(\mathrm{a})|_{2}-|\mathrm{X}(\mathrm{N}-\mathrm{a})|_{2}\right\} \\
\mathrm{G}(\mathrm{a})=\operatorname{Im}(\mathrm{E}\{\mathrm{X}(\mathrm{a}) \mathrm{X}(\mathrm{N}-\mathrm{a})\})+\frac{1}{2} \mathrm{M}(\mathrm{a}) \mathrm{E}\left\{\left|\mathrm{X}(\mathrm{a})+\mathrm{X}^{*}(\mathrm{~N}-\mathrm{a})\right|_{2}\right\} \bullet \varphi
\end{array},\right.
$$

where $\mathrm{a}=\mathrm{a}_{0}^{+}, \mathrm{a}_{1}^{+}, \ldots, \mathrm{a}_{\mathrm{N}_{1}-1}^{+}$.

Then Equation (17) can be abbreviated as:

$$
\mathrm{P}(\mathrm{a}) \bullet \theta(\mathrm{a})=\mathrm{G}(\mathrm{a}) \quad, \mathrm{a}=\mathrm{a}_{0}^{+}, \mathrm{a}_{1}^{+}, \ldots, \mathrm{a}_{\mathrm{N}_{1}-1}^{+},
$$

When the set $A$ contains 0 point and N/2 point, $\mathrm{P}=0$ at these two points, so $\theta(0)$ and $\theta(\mathrm{N} / 2)$ cannot be directly calculated by Equation (19) and require special analysis. However, when converting the algorithm to a hardware circuit, the complexity of the algorithm will increase the power consumption and cost. The variable $\varphi$ is calculated by the fitting method, and the fitting method can also be used to estimate $\theta(a)$. We propose a general fitting model that does not require special calculations for 0 point and $\mathrm{N} / 2$ point, then the purpose of simplifying the I/Q imbalance calibration model can be achieved without reducing the performance.

Establishing a polynomial fitting equation for $\theta(a)$,

$$
\theta(a)=\left[F_{1} a+F_{2} a^{2}+F_{3} a^{3}+F_{4} a^{4}\right], a=a_{0}^{+}, a_{1}^{+}, \ldots, a_{N_{1}-1}^{+},
$$

Equation (19) can be abbreviated as:

$$
\mathrm{G}=\mathrm{P}_{\mathrm{d}} \bullet \mathrm{F},
$$


with

$$
\left\{\begin{array}{l}
\mathrm{G}=\left[\mathrm{G}\left(\mathrm{a}_{0}^{+}\right), \mathrm{G}\left(\mathrm{a}_{1}^{+}\right), \ldots \mathrm{G}\left(\mathrm{a}_{\mathrm{N}_{1}-1}^{+}\right)\right]^{\mathrm{T}} \\
\mathrm{F}=\left[\begin{array}{llll}
\mathrm{F}_{1} & \mathrm{~F}_{2} & \mathrm{~F}_{3} & \mathrm{~F}_{4}
\end{array}\right]^{\mathrm{T}} \\
\left.\mathrm{P}_{\mathrm{d}}=\operatorname{diag}\left(\left[\mathrm{P}\left(\mathrm{a}_{0}^{+}\right), \mathrm{P}\left(\mathrm{a}_{1}^{+}\right), \ldots \mathrm{P}\left(\mathrm{a}_{\mathrm{N}_{1}-1}^{+}\right)\right]\right]^{\mathrm{T}}\right) \bullet \mathrm{H} \\
\mathrm{H}=\left[\begin{array}{cccc}
\mathrm{a}_{0}^{+} & \left(\mathrm{a}_{0}^{+}\right)^{2} & \left(\mathrm{a}_{0}^{+}\right)^{3} & \left(\mathrm{a}_{0}^{+}\right)^{4} \\
\mathrm{a}_{1}^{+} & \left(\mathrm{a}_{1}^{+}\right)^{2} & \left(\mathrm{a}_{1}^{+}\right)^{3} & \left(\mathrm{a}_{1}^{+}\right)^{4} \\
\vdots & \vdots & \vdots & \vdots \\
\mathrm{a}_{\mathrm{N}_{1}-1}^{+} & \left(\mathrm{a}_{\mathrm{N}_{1}-1}^{+}\right)^{2} & \left(\mathrm{a}_{\mathrm{N}_{1}-1}^{+}\right)^{3} & \left(\mathrm{a}_{\mathrm{N}_{1}-1}^{+}\right)^{4}
\end{array}\right]
\end{array}\right.
$$

The polynomial fitting objective function is:

$$
\min \left(G-P_{d} F\right)^{T} \bullet\left(G-P_{d} F\right),
$$

According to the least squares, the fitting coefficient $\mathrm{F}$ is:

$$
\mathrm{F}=\left(\mathrm{P}_{\mathrm{d}}^{\mathrm{T}} \mathrm{P}_{\mathrm{d}}\right)^{-1} \mathrm{P}_{\mathrm{d}}^{\mathrm{T}} \bullet \mathrm{G},
$$

The equation for calculating the baseband phase imbalance parameter $\theta$ is:

$$
\theta=\mathrm{H} \bullet \mathrm{F},
$$

Finally, the time-domain filter coefficients are obtained by Equation (26):

$$
\mathrm{h}_{\text {fir }}=\operatorname{Re}\left\{\operatorname{IFFT}\left[\mathrm{Me}^{\mathrm{j} \theta}\right]\right\},
$$

\subsection{I/Q Imbalance Compensation}

According to Euler's formula [36], Equation (3) can be equivalently written as:

$$
\begin{aligned}
& x(n)=x_{I}(n)+j x_{Q}(n) \\
& \quad=z_{I}(n) \otimes h_{I}(n)+j\left[z_{Q}(n) \cos \varphi-z_{I}(n) \sin \varphi\right] \otimes h_{Q}(n)
\end{aligned}
$$

According to Equation (27), the I/Q imbalance compensation structure can be obtained. The FIR real-value digital filter with coefficients $h_{\text {fir }}$ is added to the I-branch for the compensation of the frequency-dependent amplitude and phase imbalances between I and Q channels. The I-branch signal will produce group delay when passing through the FIR filter, so the output data of the Q-branch should be delayed by $\mathrm{N}_{1}$ to achieve synchronization with the I-branch. The imbalance parameter $\varphi$ is added to the I- and Q-branch to compensate the frequency-independent phase difference as shown in Figure 5.

The detailed logic block diagram of the IQ imbalance calibration model algorithm designed in this section is shown in Figure 7.

In Figure 7 , the input complex signal data is $x_{d}=\left[x_{d}(1), x_{d}(2), \ldots, x_{d}(K)\right]^{T}$. The function reshape $(x, N, W)$ represents the transformation of the column vector $x$ into an $\mathrm{N} \times W$ matrix, and $B$ is an $\mathrm{N} \times \mathrm{W}$ window coefficient matrix. The function sort() means to sort the data in descending order, where value is the new sequence after sorting, and index is the index of the item in the new sequence corresponding to the original sequence. 


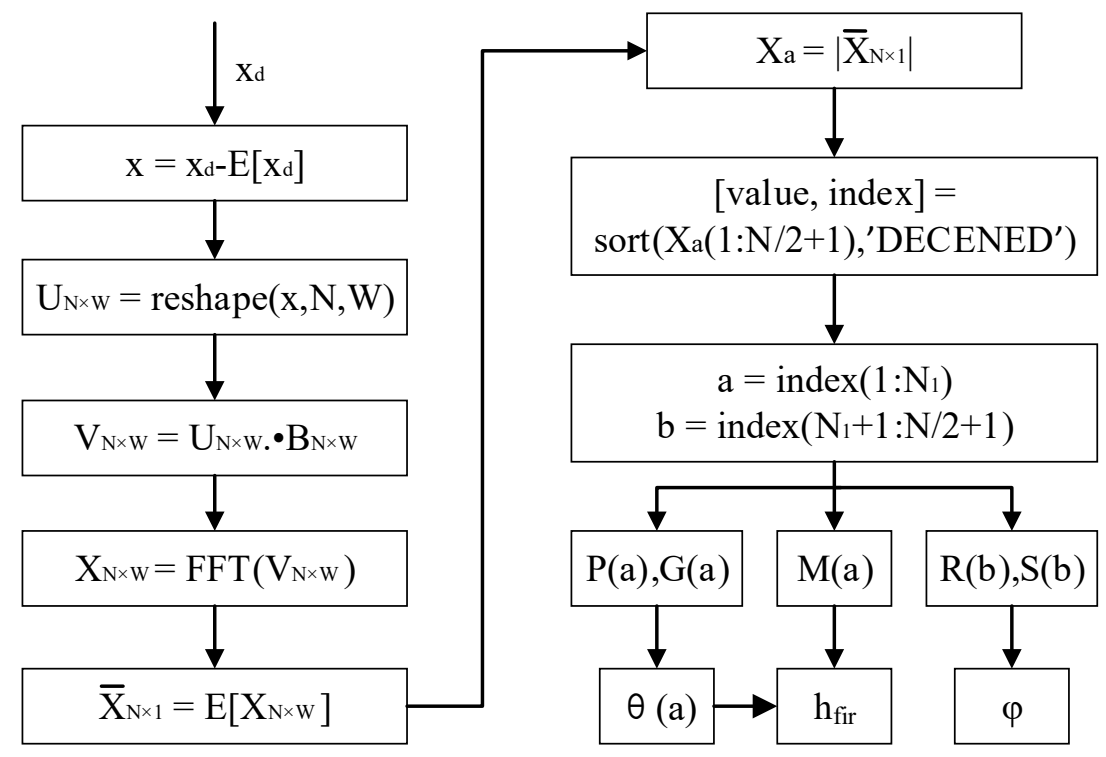

Figure 7. Algorithm logic block diagram.

\section{Simulations}

In order to verify the model mentioned in this paper, we cite two test-cases in the literature [28] for simulation, and compare the calibration effect of this model and literature $[28,30]$. The SNR is set to 25 $\mathrm{dB}$, the mismatched frequency-independent gain $\alpha=1.03$ and phase $\varphi=3^{\circ}$, the frequency-dependent imbalance parameters are as follows:

- $\quad$ Case 1: $\mathrm{h}_{\mathrm{I}}=[0.98,0.03], \mathrm{h}_{\mathrm{Q}}=[1,-0.005]$.

- Case 2: $h_{I}=[0.01,1,0.01], h_{Q}=[0.01,1,0.2]$.

In the proposed model, the larger the number of calibration points chosen, the more information is captured on the received signal. The following selects a different number of calibration points $(\mathrm{N}=4,8,16,32,64,128)$ and signal points $\left(2 \mathrm{~N}_{1}=2,4\right)$ for simulation. In the simulation, $\mathrm{f}_{\mathrm{s}}=$ $245.76 \mathrm{MHz}$. Under different configuration conditions, MATLAB is used to generate single-tone signals with frequencies of [-115:5:115] MHz, Gaussian white noise and imbalance parameters are added. In addition, this simulation also adds the DC offset parameter $\mathrm{g}=0.01$. Each single-tone signal under different configurations is tested 300 times, and 32,768 samples are used in each experiment. The simulation results are shown in Figures 8-10.

Figure 8 shows the amplitude spectrum of the single-tone signal ( $55 \mathrm{MHz}$ ) before and after imbalance compensation, respectively. The IRR of the single-tone signal before compensation is $53.1 \mathrm{dBc}$, and the IRR after compensation is $66.4 \mathrm{dBc}$ (with $13.3 \mathrm{~dB}$ improvement). The DC amplitude of the single-tone signal before compensation is $-37.3 \mathrm{dBFS}$, and the DC amplitude after calibration is $-59.6 \mathrm{dBFS}$ (with $22.3 \mathrm{~dB}$ decline). Figure 9 shows that for the proposed model, the greater number of calibration points, the higher IRR. When the number of calibration points reaches a certain level, IRR no longer significantly increases. While reference [30] uses all calibration points to fit frequency-dependent imbalance parameters, the more calibration points there are, the more unnecessary points are introduced, resulting in large errors after fitting. Figure 10 shows the distribution of IRR in the baseband before and after compensation for Case 1 and Case 2. The average IRR of the mismatch cases without compensation are $I_{R R} R_{C 1}=29.1 \mathrm{dBc}$ and $I_{R R} R_{2}=20.3 \mathrm{dBc}$. When $\mathrm{N}=64$ and $2 \mathrm{~N}_{1}=2$ (the filter length is also 2), the average simulation results of the proposed model are $I_{R} R_{C 1}=66.2 \mathrm{dBc}$, $I R R_{C 2}=65.7 \mathrm{dBc}$. With the same configuration conditions, the results of reference [28] are that when the filter length is 2 , $I R R_{C 1}=44-54 \mathrm{dBc}$; when the filter length is $3, I^{2} R_{C 2}=35-46 \mathrm{dBc}$. 


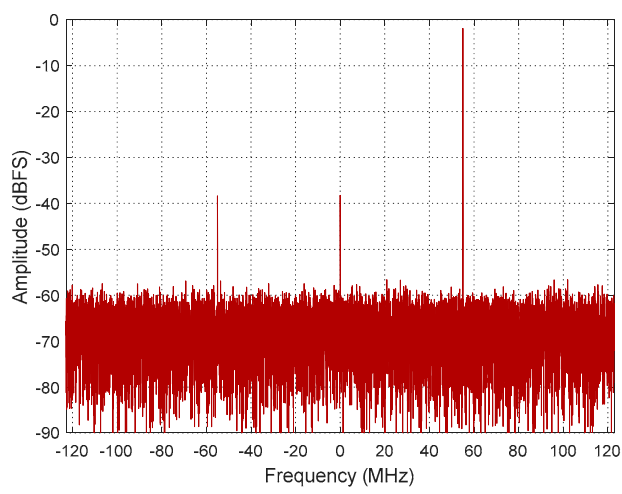

(a)

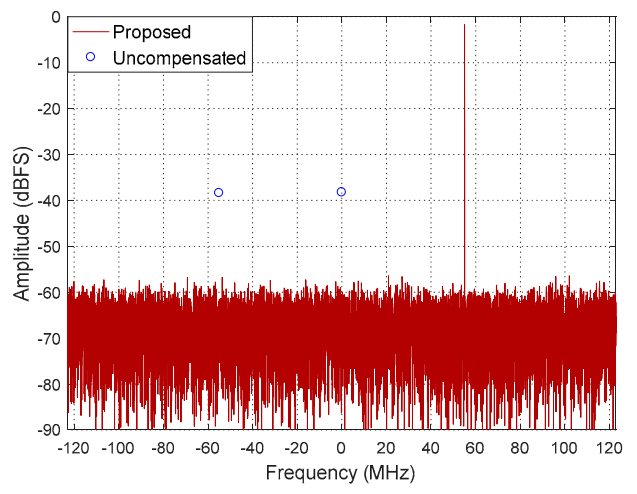

(b)

Figure 8. The amplitude spectra of single-tone signal: (a) Before imbalance compensation; (b) after imbalance compensation. The number of calibration points $\mathrm{N}=64$ and the number of signal points $2 \mathrm{~N}_{1}=2$.

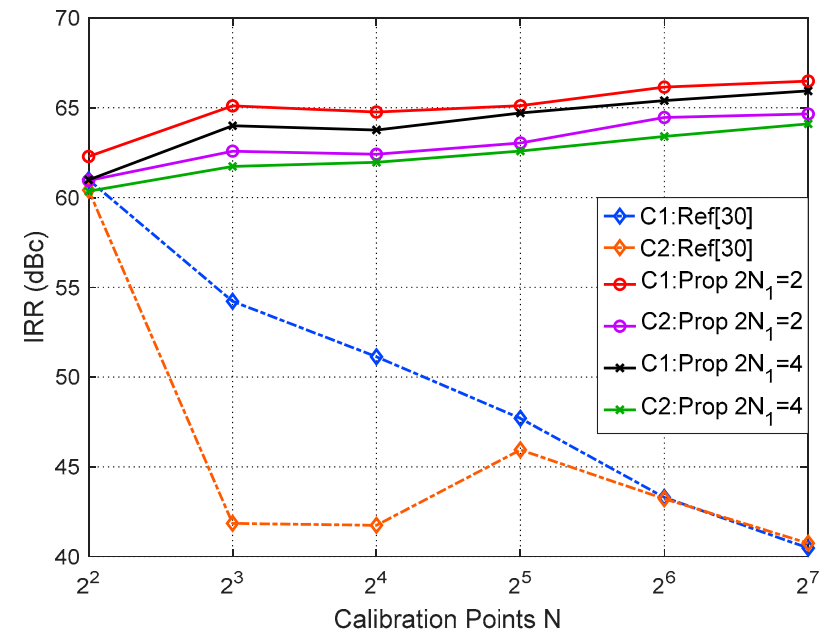

Figure 9. Spectral IRR performance of the I/Q mismatch Cases (C1/C2) with the different number of calibration points and signal points.

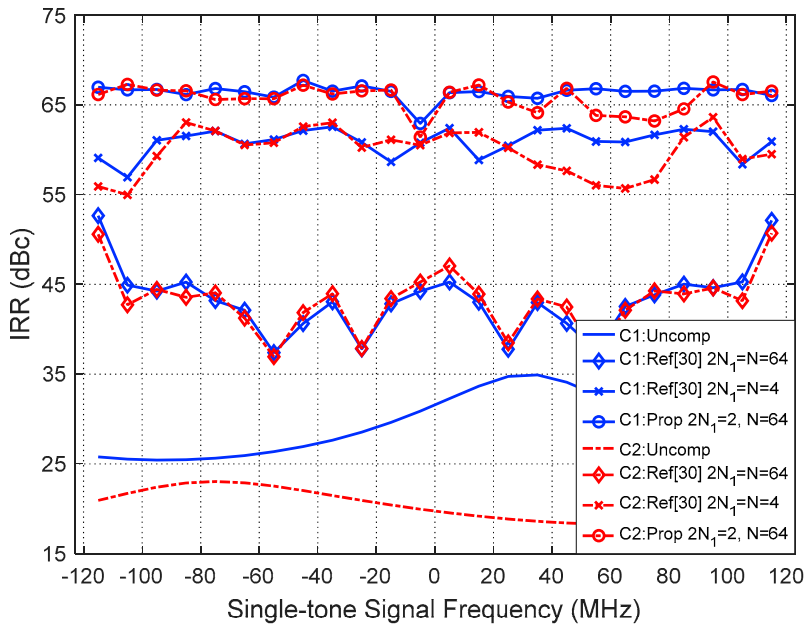

Figure 10. Spectral IRR performance of the I/Q mismatch Cases $(\mathrm{C} 1 / \mathrm{C} 2)$ in the baseband before and after compensation. 


\section{Experiments}

We use the mismatched data of the ADRV9009 receiving channel for experimental verification of the calibration model proposed in this paper. The ADRV9009 transceiver has an embedded DC offset calibration, so only the IQ imbalance calibration can be turned off. The environment for our experimental operation is shown in Figure 11. We use MATLAB [37] to build the I/Q imbalance calibration model to deal with the received mismatch data offline. The hardware modules mainly include ADI's ADRV9009 Evaluation Board, Xilinx's Zynq Evaluation Platform (EVAL-TPG-ZYNQ3) and RF signal generator. During the experiment, we turned off the I/Q calibration mode of ADRV9009 and used the Python to edit the script to call the function provided by the ADI company to read the memory (RAM) data of the Zynq evaluation platform. Then, we used the TCP protocol to establish a connection with MATLAB in order to transfer experimental data.

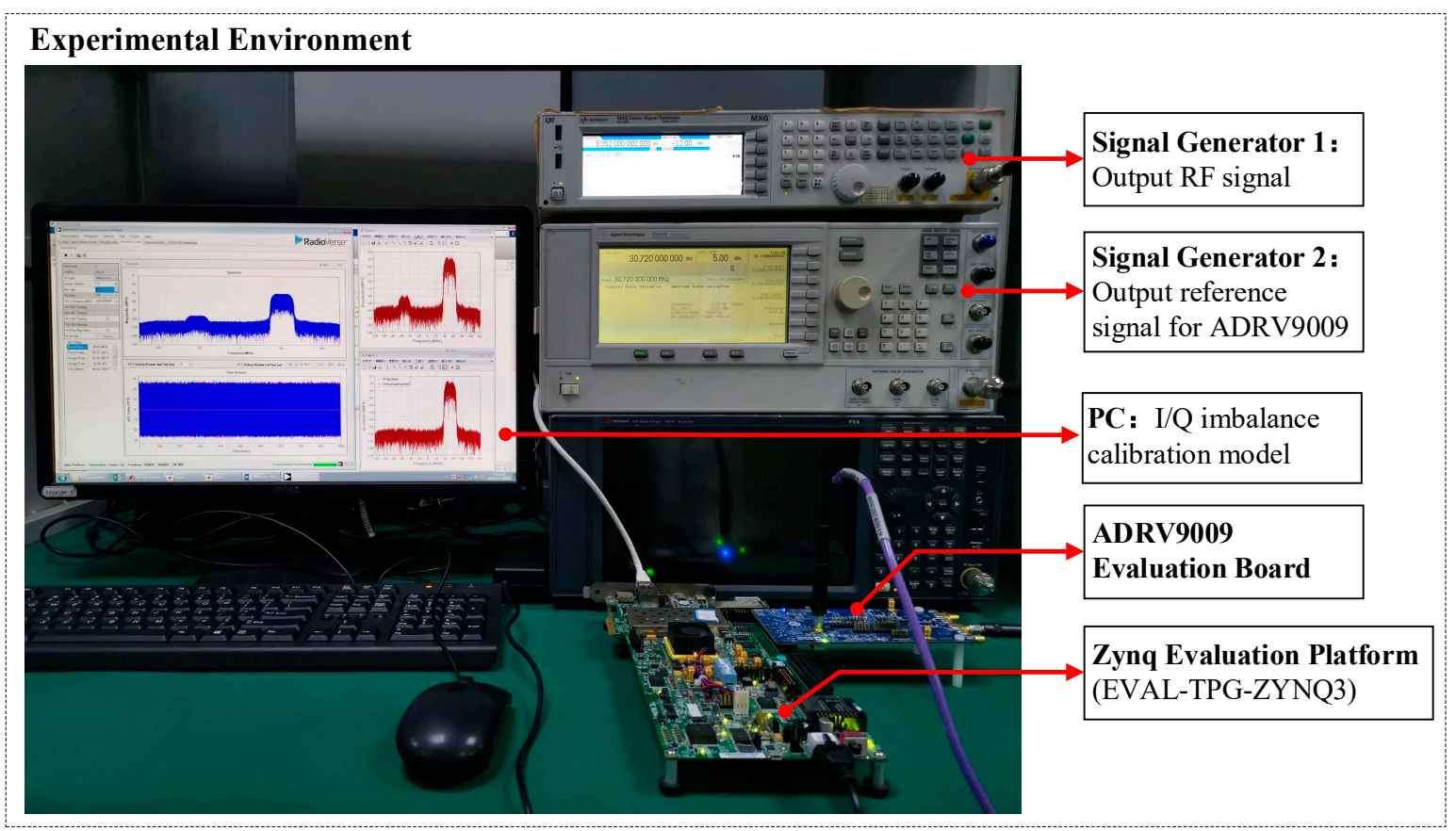

Figure 11. Experimental environment diagram.

We conducted experiments on multi-tone and wideband signals: (1) the signal generator sends a set of multi-tone signals with a frequency interval of $10 \mathrm{MHz}$, whose amplitude is $-18 \mathrm{dBm}$. The $\mathrm{LO}$ frequency of the receiving channel was configured to $3 \mathrm{GHz}$, and the channel gain is $5 \mathrm{~dB}$. (2) The signal generator sent a wideband signal with a modulation mode of quadrature phase shift keying (QPSK), configured with a roll-off factor of 0.5 , a symbol transmission rate of $20 \mathrm{Msps}$, a center frequency of $3.05 \mathrm{GHz}$, and an amplitude of $-14 \mathrm{dBm}$. The receive channel $\mathrm{LO}$ frequency was configured at $3 \mathrm{GHz}$, and the channel gain was $5 \mathrm{~dB}$.

Figures 12 and 13 exhibit the amplitude spectrum of the multi-tone and the wideband signals before and after imbalance compensation, respectively. The average IRR of the multi-tone signal before compensation is $52.2 \mathrm{dBc}$, and the average IRR after compensation is $81.6 \mathrm{dBc}$ (with $29.4 \mathrm{~dB}$ improvement). The wideband signal has the largest amplitude at $45.6 \mathrm{MHz}$ before compensation, its IRR is $48.7 \mathrm{dBc}$, and the IRR after compensation at this frequency is $75.9 \mathrm{dBc}$ (with $27.2 \mathrm{~dB}$ improvement). The above experimental results show good calibration effect of the proposed I/Q imbalance calibration model on both multi-tone and wideband signals. 


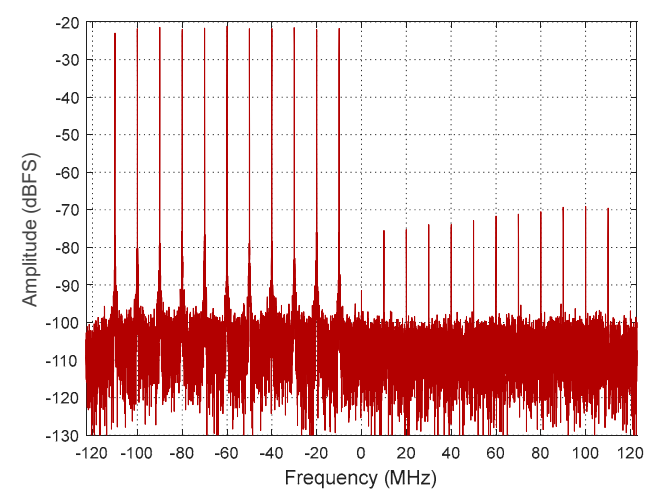

(a)

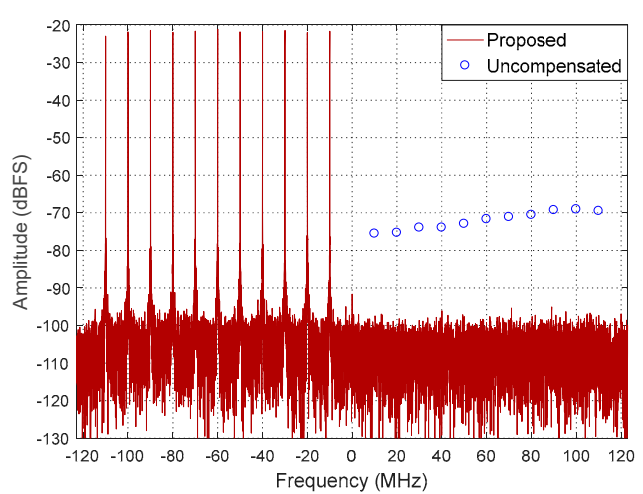

(b)

Figure 12. The amplitude spectra of multi-tone signal: (a) before imbalance compensation; (b) after imbalance compensation. The number of calibration points $\mathrm{N}=64$ and the number of signal points $2 \mathrm{~N}_{1}=56$.

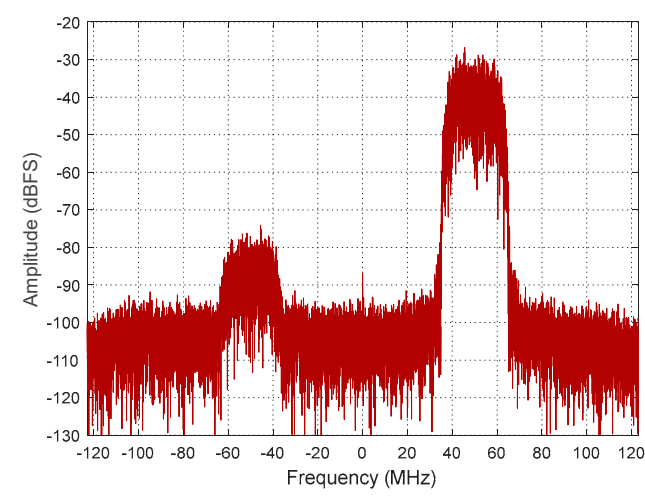

(a)

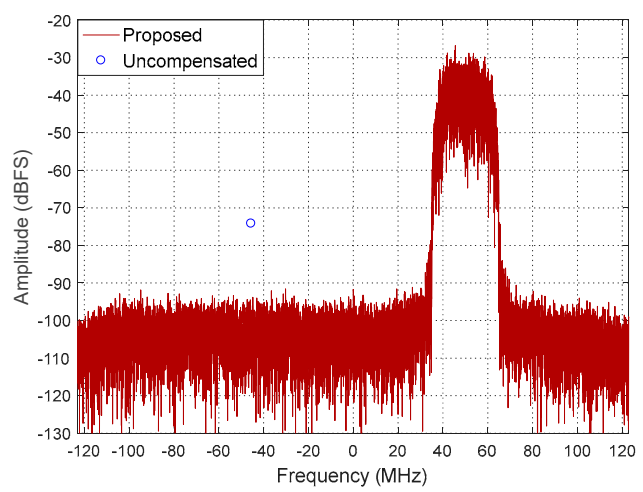

(b)

Figure 13. The amplitude spectra of wideband signal: (a) before imbalance compensation; (b) after imbalance compensation. The number of calibration points $\mathrm{N}=64$ and the number of signal points $2 \mathrm{~N}_{1}=2$.

\section{Conclusions}

This paper designs a blind calibration model for the IQ imbalance problem of zero-IF receiver. Based on the existing frequency-domain blind calibration algorithm, we propose a calibration point classification rule based on the distribution characteristics of imbalance parameters, which successfully separates frequency-dependent phase imbalance and frequency-independent phase imbalance, eliminates the interference of useless information, and reduces the filter length. We also add a simple DC calibration algorithm to reduce the impact of DC offset on IQ calibration. In order to simplify the hardware implementation of the algorithm, we propose a general phase imbalance parameter fitting method, which does not require special analysis of the 0 point and the N/2 point. We use MATLAB to build an IQ calibration model for simulation and experimentation. The simulation results show IRR improvement to around $35-45 \mathrm{dBc}$ at high SNR, and the DC component reduced by $10 \mathrm{~dB}$. The experimental results exhibit the IRR improvement of both multi-tone and wideband signals to about $30 \mathrm{dBc}$. The flatness of the digital compensation filter will affect the IQ imbalance calibration effect of the received mismatch signal. The calculated IQ imbalance compensation factor has a calibration effect on a stable frequency signal. Therefore, how to improve the flatness of the filter and design the start-up cycle of the estimation module to reduce the cost and power consumption will be the focus of our following research. 
Author Contributions: Methodology, X.P.; software, Z.W.; validation, C.W.; data curation, J.M.; writing-original draft preparation, X.P.; writing-review and editing, Z.W.; supervision, F.Y.; project administration, J.L.; funding acquisition, J.M. All authors have read and agreed to the published version of the manuscript.

Funding: This research was supported in part by the National Natural Science Foundation of China Grant 61604128.

Acknowledgments: The authors would like to thank the Institute of Aerospace Electronics Engineering of Zhejiang University for providing a research platform and technical support.

Conflicts of Interest: The authors declare no conflict of interest.

\section{References}

1. Meshram, S.; Kolhare, N. The advent software defined radio: FM receiver with RTL SDR and GNU radio. In Proceedings of the 2019 International Conference on Smart Systems and Inventive Technology (ICSSIT), Tirunelveli, India, 27 November 2019; pp. 230-235.

2. Wicaksono, A.; Mauludiyanto, A.; Hendrantoro, G. An HF digital communication system based on software-defined radio. In Proceedings of the 2020 International Conference on Smart Technology and Applications (ICoSTA), Surabaya, Indonesia, 20 February 2020; pp. 1-5.

3. Gao, Y.; Jiang, W. Wideband photonic RF transceiver with zero-if architecture. In Proceedings of the 2017 International Topical Meeting on Microwave Photonics (MWP), Beijing, China, 23-26 October 2017; pp. 1-4.

4. Mabrouk, K.; Huyart, B.; Neveux, G. 3-D aspect in the five-port technique for zero-IF receivers and a new blind calibration method. IEEE Trans. Microw. Theory Tech. 2008, 56, 1389-1396. [CrossRef]

5. McLaurin, D.J. A highly reconfigurable 65nm CMOS RF-to-bits transceiver for full-band multicarrier TDD/FDD 2G/3G/4G/5G macro basestations. In Proceedings of the 2018 IEEE International Solid-State Circuits Conference-(ISSCC), San Francisco, CA, USA, 11-15 February 2018; pp. 162-164.

6. DeWitt, J.J. Modelling Estimation and Compensation of Imbalances in Quadrature Transceivers. Ph.D. Thesis, Cape Town University of Stellenbosch, Stellenbosch, South Africa, 2011.

7. Chia-Ling, L. Impacts of I/Q imbalance on QPSK-OFDM-QAM detection. IEEE Trans. Consum. Electron. 1998, 44, 984-989. [CrossRef]

8. Faulkner, M.; Mattsson, T.; Yates, W. Automatic adjustment of quadrature modulators. Electron. Lett. 1991, 27, 214-216. [CrossRef]

9. Valkama, M.; Renfors, M.; Koivunen, V. Compensation of frequency-selective I/Q imbalances in wideband receivers: Models and algorithms. In Proceedings of the 2001 IEEE Third Workshop on Signal Processing Advances in Wireless Communications (SPAWC'01). Workshop Proceedings (Cat. No.01EX471), Taiwan, China, 20-23 March 2001; pp. 42-45.

10. Li, W.; Zhang, Y.; Huang, L.; Cosma, J.; Maple, C.; Xiong, J. Self-IQ-demodulation based compensation scheme of frequency-dependent IQ imbalance for wideband direct-conversion transmitters. IEEE Trans. Broadcast. 2015, 61, 666-673. [CrossRef]

11. Lei Zhigang, L.; Xiantao, C.; Shaoqian, L. Golay sequence based time-domain compensation of frequency-dependent I/Q imbalance. China Commun. 2014, 11, 1-11.

12. Lin, H.; Zhu, X.; Yamashita, K. Low-complexity pilot-aided compensation for carrier frequency offset and I/Q imbalance. IEEE Trans. Commun. 2010, 58, 448-452. [CrossRef]

13. Xing, G.; Shen, M.; Liu, H. Frequency offset and I/Q imbalance compensation for direct-conversion receivers. IEEE Trans. Wireless Commun. 2005, 4, 673-680. [CrossRef]

14. Tarighat, A.; Bagheri, R.; Sayed, A.H. Compensation schemes and performance analysis of IQ imbalances in OFDM receivers. IEEE Trans. Signal Process. 2005, 53, 3257-3268. [CrossRef]

15. Sung, K.Y.; Chao, C.C. Estimation and compensation of I/Q imbalance in OFDM direct-conversion receivers. IEEE J. Sel. Topics Signal Process. 2009, 3, 438-453. [CrossRef]

16. Wang, X.; Wang, S.B.; Li, C.X.; Zhang, R.S. Two-dimensional decomposition LUT correction for I/Q imbalance in reconfigurable wideband receivers. In Proceedings of the 2019 IEEE MTT-S International Wireless Symposium (IWS), Guangzhou, China, 19-22 May 2019; pp. 1-3.

17. De Witt, J.J.; Van Rooyen, G. A blind I/Q imbalance compensation technique for direct-conversion digital radio transceivers. IEEE Trans. Veh. Technol. 2009, 58, 2077-2082. [CrossRef]

18. Lin, H.; Thaiupathump, T.; Kassam, S.A. Blind separation of complex I/Q independent sources with phase recovery. IEEE Signal Process. Lett. 2005, 12, 419-422. [CrossRef] 
19. Valkama, M.; Renfors, M.; Koivunen, V. Advanced methods for I/Q imbalance compensation in communication receivers. IEEE Trans. Signal Process. 2001, 49, 2335-2344. [CrossRef]

20. Zekkari, C.; Djendi, M.; Guessoum, A. Efficient adaptive filtering algorithm for IQ imbalance compensation Tx/Rx systems. IET Signal Process. 2018, 12, 566-573. [CrossRef]

21. Ellingson, S.W. Correcting IQ Imbalance in Direct Conversion Receivers; Virginia Polytechnic Institute and State University: Virginia, VA, USA, 2003; pp. 25-32.

22. Rykaczewski, P.; Jondral, F. Blind I/Q imbalance compensation in multipath environments. In Proceedings of the 2007 IEEE International Symposium on Circuits and Systems, New Orleans, LA, USA, 27-30 May 2007; pp. 29-32.

23. Anttila, L.; Valkama, M. Blind signal estimation in widely-linear signal models with fourth-order circularity: Algorithms and application to receiver I/Q calibration. IEEE Signal Process. Lett. 2013, 20, 221-224. [CrossRef]

24. Anttila, L.; Valkama, M.; Renfors, M. Circularity-based I/Q imbalance compensation in wideband direct-conversion receivers. IEEE Trans. Veh. Technol. 2008, 57, 2099-2113. [CrossRef]

25. Valkama, M.; Renfors, M.; Koivunen, V. Blind signal estimation in conjugate signal models with application to I/Q imbalance compensation. IEEE Signal Process. Lett. 2005, 12, 733-736. [CrossRef]

26. Nam, W.; Roh, H.; Lee, J.; Kang, I. Blind adaptive I/Q imbalance compensation algorithms for direct-conversion receivers. IEEE Signal Process. Lett. 2012, 19, 475-478. [CrossRef]

27. Song, P.; Zhang, N.; Zhang, H.; Gong, F. Blind estimation algorithms for I/Q imbalance in direct down-conversion receivers. In Proceedings of the 2018 IEEE 88th Vehicular Technology Conference (VTC-Fall), Chicago, IL, USA, 27-30 August 2018.

28. Petit, M.; Springer, A. Analysis of a properness-based blind adaptive I/Q filter mismatch compensation. IEEE Trans. Wirel. Commun. 2016, 15, 781-793. [CrossRef]

29. Tsai, Y.; Yen, C.; Wang, X. Blind frequency-dependent I/Q imbalance compensation for direct-conversion receivers. IEEE Trans. Wirel. Commun. 2010, 9, 1976-1986. [CrossRef]

30. Wei, A.; Brian, R.; Richard, P.S. Real-time I/Q Imbalance Correction for Wide-Band RF Receiver. U.S. Patent 10,050,744 B2, 14 August 2018.

31. Wei, A.; Yosef, S. System and Methods for Narrowband Signal Quadrature Error Correction. U.S. Patent 9,306,782 B2, 5 April 2019.

32. Lin, H.; Yamashita, K. Time domain blind I/Q imbalance compensation based on real-valued filter. IEEE Trans. Wirel. Commun. 2012, 11, 4342-4350. [CrossRef]

33. Inamori, M.; Bostamam, A.M.; Sanada, Y.; Minami, H. IQ imbalance compensation scheme in the presence of frequency offset and dynamic DC offset for a direct conversion receiver. IEEE Trans. Wirel. Commun. 2009, 8, 2214-2220. [CrossRef]

34. Alan, V.; Oppenheim Alan, S.; Willsky, S.; Hamid, N. Signals and Systems, 2nd ed; Publishing House of Electronics Industry: Bejing, China, 2013; p. 238.

35. Hsu, C.; Cheng, R.; Sheen, W. Joint least squares estimation of frequency, DC offset, I-Q imbalance, and channel in MIMO receivers. IEEE Trans. Veh. Technol. 2009, 58, 2201-2213. [CrossRef]

36. Wang, E.; Nian, G.; Wang, K. Euler's formula in computing hyper-complex fourier transform. In Proceedings of the 2011 4th International Congress on Image and Signal Processing, Shanghai, China, 15-17 October 2011; pp. 755-759.

37. Ingle, V.K.; Proakis, J.G. Digital Signal Processing Using MATLAB; Xi'an Jiaotong University Press: Xi'an, China, 2018; p. 1.

Publisher's Note: MDPI stays neutral with regard to jurisdictional claims in published maps and institutional affiliations.

(C) 2020 by the authors. Licensee MDPI, Basel, Switzerland. This article is an open access article distributed under the terms and conditions of the Creative Commons Attribution (CC BY) license (http://creativecommons.org/licenses/by/4.0/). 